\title{
Physical safety and multiple land use
}

\author{
SHAHID I. SUDDLE \\ Faculty of Civil Engineering and Geosciences, Delft University of Technology, 5048, 2600 GA, Delft, \\ The Netherlands; Stadsgewest Haaglanden, Grote Marktstraat 43, 66, 2501 CB, The Hague, The \\ Netherlands \\ E-mail: s.i.suddle@tudelft.nl; suds@haaglanden.nl; phone: +31-6-300-76869; fax: +31-70-75015961
}

\begin{abstract}
Multiple land use brings with it several safety risks when buildings are developed above or nearby transport routes of hazardous materials. To reduce these risks several measures can be implemented in multiple land-use projects for both the construction and the exploitation stage. These measures will reduce either the probability and/or the consequences of an incident, but also influence the potential to develop those projects in their design and layout. This paper gives an analysis of physical and spatial safety for both the construction and exploitation stages in multiple land-use projects, and gives an overview of the spatial implications for these projects.
\end{abstract}

Key words: multiple land use, safety, safety measures, transport of hazardous materials, urban development

\section{Introduction}

A shortage of land across the Netherlands and in most countries of Western Europe has led to the development of design and construction techniques that make intensive and multiple use of the limited space possible. In the last decade, the space available above transport infrastructure - such as roads and railway tracks - and existing buildings have been used at a growing rate in city centres. The new development strategies regarding space in urban areas pay particular attention to these issues. However, the Dutch spatial planning policy, which aims to intensify the use of space, may come into conflict with the intentions set out in the Fourth National Environmental Policy Plan, which states that additional space is sometimes necessary to guarantee external safety (V\&W/VROM, 2003). Several places are characterised by exceeding the acceptability and tolerability criterion of safety, due to transport of hazardous materials (RIVM, 1998). Remarkably, these areas, in which transport of hazardous materials takes place, are the same areas for which the Fifth National Policy Document on Spatial Planning of the Netherlands desires intensification, multiple land use and transformation (VROM, 2001).

Because the use of space is being intensified near locations with potentially dangerous activities (e.g. industrial activities and transport routes or storage of hazardous materials), any accident may have serious consequences (Ale, 2003). In general, due to safety considerations and an acceptable level for group risk, there is an inverse relation between the population density and the number of transported dangerous goods in a specific area. The higher the number of transported hazardous materials, the lower the population density that can be allowed (see Figure1). Focussing on the local project scale, it can be stated that projects using land in multiple ways are generally complex. The safety considerations in multiple land-use projects should not be underestimated. Usually, a large number of people and several multiple risk interactions are involved. Due to the complexity and interrelationships of such a project, a small accident, like a fire in the building or on the covered infrastructure, can easily lead to a major disaster. Therefore, safety is one of the critical issues in such projects during construction as well as in the exploitation stage. Moreover, major accidents all over the world, particularly in cases in which a great number of casualties were involved, have influenced the perception of safety (Vlek, 1995).

This paper gives an analysis of possibilities of how to deal with an acceptable and an economically viable safety level in multiple-used urban areas, especially for those cases where transport of hazardous materials will increase in the future. 


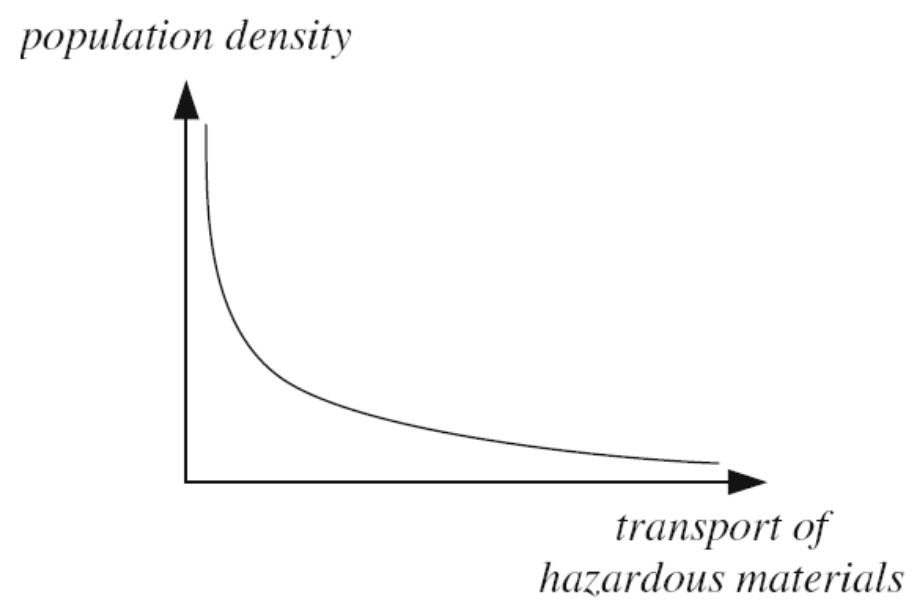

Figure 1. Inverse relation between the population density and the number of transported dangerous goods. Source: Suddle (2004).

The paper is based on the Ph.D. research by Suddle (2004). The article is structured as follows. In Section 2 the main elements of physical safety in relation to multifunctional land use are explained. For this purpose we introduce four hazard scenarios. In Section 3 the safety chain is introduced as a way to analyse the effects of various safety measures. Here the emphasis is on measures which have a spatial effect. Measures may influence the design or the layout of the project. In the fourth section we look at some of the safety measures more closely to conclude that some measures are hard to combine. For instance, the same measure increases the physical risk in one hazard scenario while decreasing the physical risk in an other one. In Section 5 some conclusions on the feasibility of safety measures in multiple land-use projects are drawn.

\section{Physical safety and multiple land use}

Probabilistic risk analyses can be undertaken to assess the safety level and to examine the required safety measures that are needed to develop these projects. When doing this risk analysis, the results have to be checked for compliance with the risk acceptance criteria. If the results do not comply with these risk acceptance criteria, extra measures can be taken to reach a certain level of safety. These measures have to be economically viable. The risk analysis should examine the construction stage and when the building is in use, for four different situations (Figure 2):

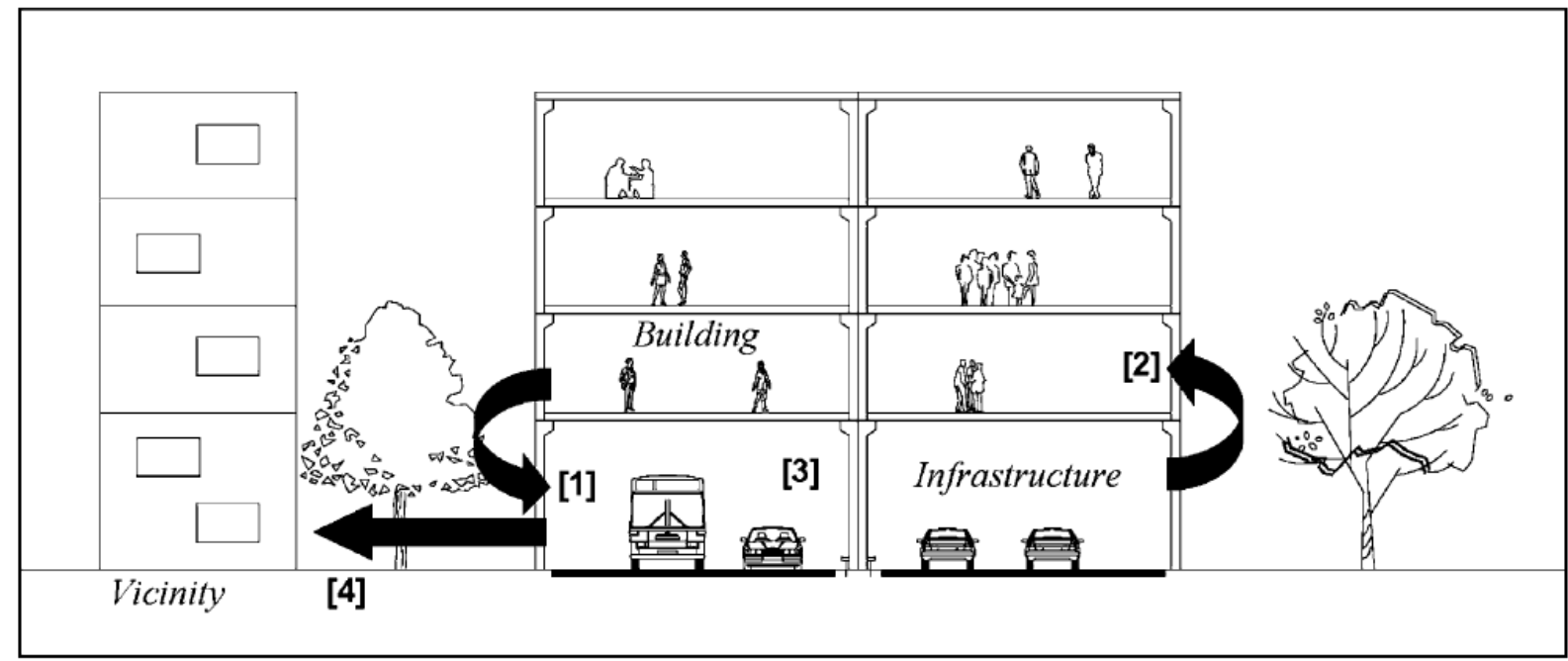

Figure 2. The four risk interactions in multiple land-use projects. Source: Suddle (2004).

- Risk dimension [1]: External safety and risks from the building in relation to the infrastructure beneath (e.g. falling elements and fire); 
- Risk dimension [2]: External safety and risks from the infrastructure towards the building (e.g. release of toxic gasses, fire, explosions and collisions against building structure);

- Risk dimension [3]: Internal safety and risks from the constructions enclosing the infrastructure (e.g. explosions, fire, explosions and collisions against building structure);

- Risk dimension [4]: External safety and risks from the infrastructure towards the vicinity (e.g. release of toxic gasses, fire, explosions and collisions against building structure).

In order to determine the effect of safety measures on both human and economic risks, one should integrate and verify these measures by risk analysis. The measures, which are normally part of the safety chain (see Section 3), can be integrated in the architectural and functional design of the building or project (if possible), while normal safety measures are only a cost-raising factor. From a decision point of view, it is a necessary strategy to balance costs and benefits of such measures and their contribution to physical safety. Besides, when a risk analysis is performed, it is important to realise that decision-making about risks is very complex, and not only technical aspects but also economic, environmental, comfort-related, political and psychological aspects, as well as societal acceptance, play an important role (Suddle and Waarts, 2003).

Physical safety in the construction stage has been analysed by Meijer and Visscher (2001). Their case studies of projects situated above the motorway 'Utrechtse Baan' in The Hague showed that the falling elements form a major hazard for third parties, such as the users of the infrastructure, because usually the infrastructure is in use when the building above it is constructed. A so-called FMEA (Failure Mode and Effect Analysis) is performed to investigate this hazard further, as presented by Suddle (2001). The falling objects can be bolts, screws, part of concrete (structures), parts of a scaffold, building parts, hammers, beams, facade elements or even construction workers. Hence, these falling elements may cause casualties among people present at the infrastructure and in some cases economic risks as well. Although it is not investigated, it can be stated that safety during the demolition stage of these projects will be similar to the safety during construction of such projects. During the construction of these projects, hazards related to the 'mechanical load' of the falling elements are the main interest. Yet the hazards arising during the exploitation are also related to the load caused by 'chemical' background of hazards (Suddle 2004). A qualitative risk analysis is performed for people in the neighbourhood of multiple land-use projects using FMEA techniques for the four interrelations between three areas (infrastructure, building and vicinity; see Figure 2). It appeared from the FMEA that the risk for people either in the building above the infrastructure or at the infrastructure or in the vicinity during the exploitation stage largely depends on the hazards taking place on the infrastructure or the hazards taking place in the building. The hazard scenarios that may occur on the infrastructure are collisions, fires, explosions, and leaks of toxic substances (consecutively decreasing in probability of occurrence and increasing in consequences; see Table 1). These accidents can also be the starting points of others. A fire for instance can cause an explosion and vice versa. The release of toxic gasses hardly initiates other events. In contrast, the hazards in the building (above the infrastructure) are mainly fire, explosions and in some cases (with a very low probability of occurrence) falling objects.

Table 1 shows qualitatively the frequencies and consequences for the four hazard scenarios that may occur on the covered infrastructure. For instance, the probability that an explosion will occur in the (covered) infrastructure is quite small, but the consequences of that scenario could be quite large in the number of people killed or injured and in the amount of economic damage.

Table 1. Frequency and consequences of hazard scenarios in multiple land-use projects with covered infrastructure

\begin{tabular}{lllll}
\hline Frequency & Consequences & & & \\
\cline { 2 - 4 } & Low & Medium & High & Extremely high \\
\hline Extremely high & $\begin{array}{l}\text { Local traffic accidents } \\
\text { and small fires }\end{array}$ & $\begin{array}{l}\text { Fires on the } \\
\text { infrastructure }\end{array}$ & Explosions & \\
High & & & Release of toxic gasses \\
Medium & & & &
\end{tabular}

Source: Adapted from Suddle (2004). 

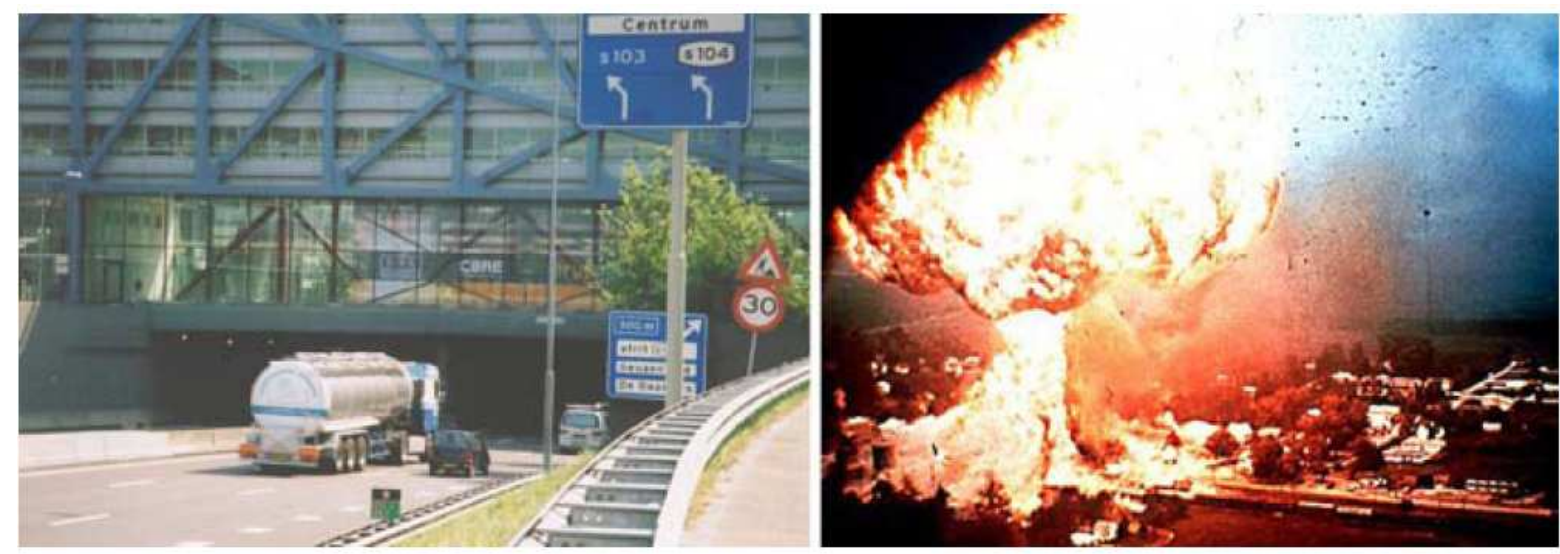

Figure 3. The transport of LPG (Liquefied Petroleum Gas) may cause an explosion, resulting in a fireball with an effect diameter of more than $300 \mathrm{~m}$.

In contrast, the probability of a traffic accident is relatively high and resulting in few fatalities. The release of toxic gasses results in a large number of people killed because the effect distance of this hazard is large (e.g. $5 \mathrm{~km}$ ). An example of the explosion scenario is presented in Figure 3; the transport of LPG (Liquefied Petroleum Gas) may cause an explosion, resulting in a fireball with an effect diameter of more than $300 \mathrm{~m}$.

\section{The application of the safety chain in multiple land use}

In general, safety measures are implemented to increase safety levels to a certain level. There are several measures that can be implemented against hazard scenarios in multiple land-use projects. These measures will reduce the probability and/or the consequences of an incident in the building above the infrastructure, in the vicinity, or in the covered infrastructure itself. From a risk management point of view, it is desired that the implemented measures should be cost effective. Note that the effects of measures are, in principle, unique to each multiple land-use project, depending on the traffic characteristics and local circumstances. A general effect of the measures applicable to all projects can therefore not be generated. Likewise, the costs of measures vary for each type of project. Nevertheless, some possibilities of safety measures in such projects can be analysed. One of the most frequently used classifications of safety measures by the Ministry of Interior and Kingdom Relations (BZK, 2000), which is responsible for upholding standards regarding safety, is the so-called safety chain.

The safety chain is formulated in order to classify the moment of action of the safety measures. This makes it possible to present the moment of implementing measures on particular events before, during or after an accident. Generally, the safety chain consists of five levels, ranging from pro-active measures in the planning phase of a project to follow-up measures after the incident itself. These are presented in Table 2.

Table 2. The five levels of the safety chain and their objective s (BZK, 2000)

\begin{tabular}{ll}
\hline Level of safety chain & Objective of safety measure \\
\hline Pro-action & Safety measures in planning phase \\
Prevention & Measures and provisions to prevent accidents \\
Preparation & Preparation and provisions to prevent accidents \\
Repression & Actions during accident (mitigation measures) \\
Follow-up & Dealing with post-accident situations \\
\hline
\end{tabular}

Source: BZK (2000).

\subsection{Physical safety measures for the construction stage}

The safety chain can be applied to analyse the safety measures for the construction stage, as well as in the exploitation stage. A pro-active safety measure could be the application of a specific construction method, by which the number of falling elements can be decreased. An example of such a measure is pumping concrete instead of erecting large elements. Structural or functional measures, which originate from the prevention level of the safety chain, can be taken to prevent falling elements reaching third parties. This can be accomplished by applying a protection canopy. Structural safety 
measures can be integrated in the architectural, functional and structural design of the building above the infrastructure. The disadvantage of temporary structural safety measures is that these are a costraising factor in projects. In contrast, if permanent safety measures are implemented, synergetic effects can be achieved; the safety for third parties can be guaranteed and the designer can bring out a multifunctional design, by which extra costs for removing the safety measure can be saved (seeFigure4). Other preventive and logistic measures could involve closing off the road and rerouting the traffic. The advantage of these last measures is that they are quite cost effective.

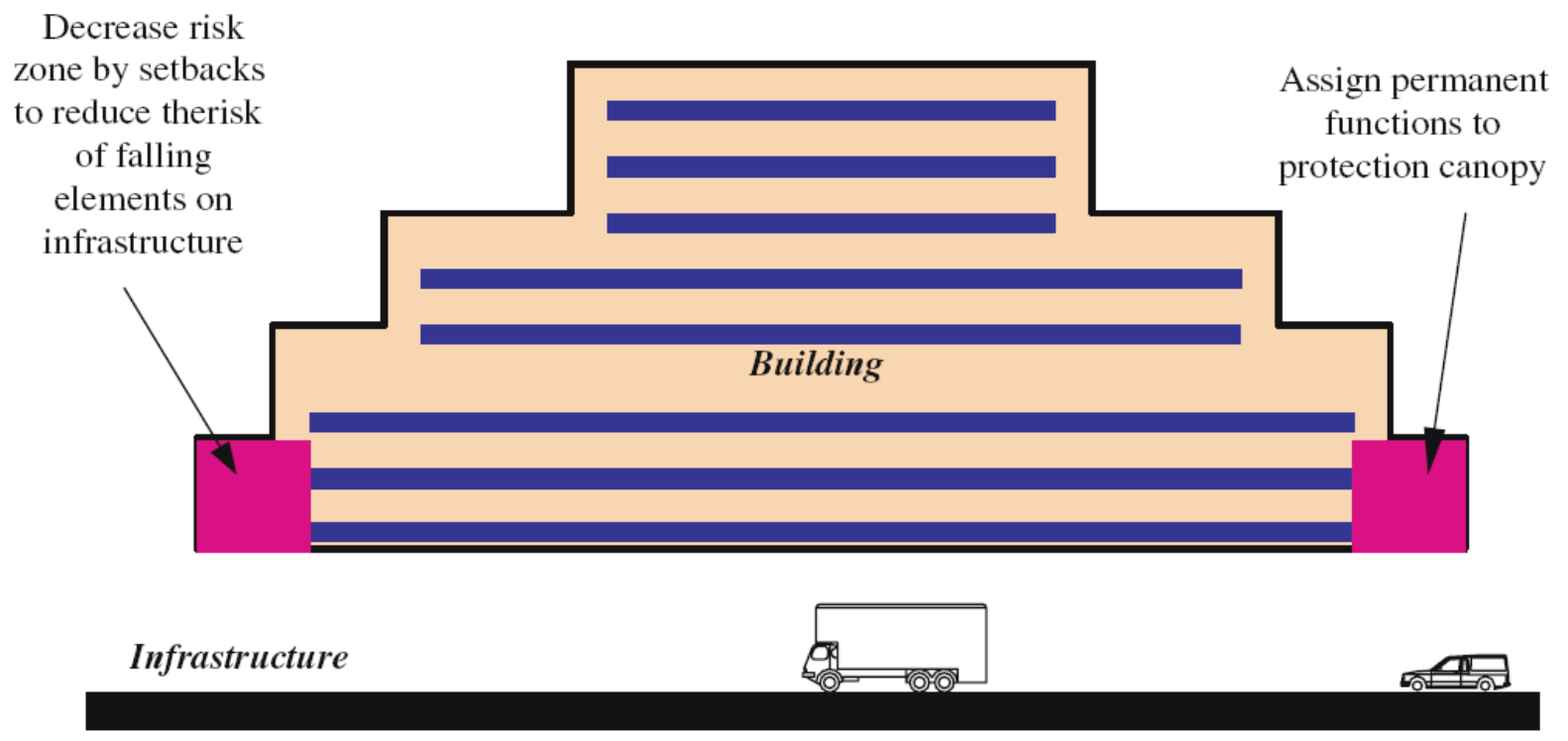

Figure 4. Improvement of the safety for third parties can be realised by set-backs in the form of the building. Source: Suddle (2004).

\subsection{Physical safety measures for the exploitation stage}

When considering the exploitation stage in multiple land-use projects, safety measures can be implemented within (the boundaries of) areas, such as the building above the infrastructure, the infrastructure itself and the vicinity. When the safety chain is considered for the exploitation stage, some general examples of safety measures of each level of the safety chain can be given (Table 3 ). After the explanation of measures of Table 3, we will focus on the possibility of implementing safety measures in such projects with functional consequences in Section 4. These are measures in the following levels of the safety chain: pro-action, prevention and repression. In Section 5, the effect on safety by spatial configuration of the covered infrastructure is treated.

\section{Functional safety measures}

A very traditional and pro-active measure to implement is to separate the transport of hazardous materials from normal traffic. However, banning transport of dangerous goods may create unjustified economic costs (OECD, 2001). Moreover, it may force operators to use even more dangerous routes such as through densely populated areas - and thus increase the overall risk. Also, rerouting transport flows may change the location preferences of firms because transportation costs will (in most cases) rise. This can have effects on a regional scale.

Another proactive measure is the development of functions concerning a low density of population on top of and along the infrastructure, such as a park or parking garages. Through this measure, the number of people exposed to the risk of the transported goods can be minimised (see Figure 1). The ultimate pro-active measure is to prohibit construction above infrastructure on which the transport of such materials takes place. This, however, diminishes the potential of MLU projects. Other functional measures are the development of uni-or bi-directional tubes for infrastructure below the building to prevent frontal collisions, thereby reducing the second risk dimension (see Figure 2). 
Table 3. Examples of safety measures in the exploitation phase of each level of the safety chain

\begin{tabular}{|c|c|c|}
\hline $\begin{array}{l}\text { Level of } \\
\text { safety chain }\end{array}$ & Safety measure & Effect of the safety measure \\
\hline \multirow[t]{3}{*}{ Pro-action } & $\begin{array}{l}\text { Nationwide ban on transport of } \\
\text { hazardous materials }\end{array}$ & No accident with hazardous materials \\
\hline & $\begin{array}{l}\text { Rerouting transport of hazardous } \\
\text { materials }\end{array}$ & $\begin{array}{l}\text { No accident with hazardous materials in } \\
\text { densely populated areas }\end{array}$ \\
\hline & Explosion-resistant walls for tunnel & $\begin{array}{l}\text { Consequences will be minimised for building } \\
\text { above }\end{array}$ \\
\hline \multirow[t]{4}{*}{ Prevention } & Reducing the speed limit & Decrease accident frequency \\
\hline & $\begin{array}{l}\text { Fire resistant walls covered } \\
\text { infrastructure }\end{array}$ & $\begin{array}{l}\text { Consequences will be minimised for } \\
\text { buildings above }\end{array}$ \\
\hline & & $\begin{array}{l}\text { Collapse of the tunnel structure is not } \\
\text { possible }\end{array}$ \\
\hline & Functional measures in the building & Population at risk is small \\
\hline Preparation & $\begin{array}{l}\text { Evacuation plan for people in the } \\
\text { building }\end{array}$ & Population at risk is small \\
\hline \multirow[t]{4}{*}{ Repression } & Structural measures on buildings & $\begin{array}{l}\text { Minimises damage to buildings and risk for } \\
\text { people }\end{array}$ \\
\hline & $\begin{array}{l}\text { Sprinklers in covered infrastructure or } \\
\text { building }\end{array}$ & Prevents escalation of fire \\
\hline & Ventilation in covered infrastructure & Prevents escalation of fire \\
\hline & Medical care/emergency response & Minimises wounded/people killed \\
\hline Follow-up & $\begin{array}{l}\text { Replacement of equipment after } \\
\text { damage made easier }\end{array}$ & $\begin{array}{l}\text { Return to the normal situation as soon as } \\
\text { possible }\end{array}$ \\
\hline
\end{tabular}

Source: Suddle (2004).

Preventive measures such as reducing the speed limit and regulating traffic can be effective as well; lowering the speed limit reduces the probability of traffic accidents and collisions on the infrastructure. On railway tracks where buildings on top of it are realised, side rails and crossings should not be applied; this precaution sharply reduces the probability of a derailment scenario.

Safety measures aiming at evacuation of human beings are mostly based on the possibility for people in an emergency situation to escape and on the availability and accessibility of emergency response, such as the fire brigade and ambulances. In essence, these are mostly measures in the preparation class of the safety chain and should be implemented in buildings above the infrastructure and in the infrastructure itself.

Repressive measures of a structural nature can be implemented on (boundaries of) the building above the infrastructure or the infrastructure itself. For instance, buildings above the infrastructure can be designed column free on the footprint of the infrastructure (see Figure 5). This is, of course, not a general design solution; it is mostly the result of architectural considerations. By this measure, the probability of a collision of a vehicle with the main structure of the building will decrease. Note that if one can utilise independent foundations for the infrastructure, one can achieve safety advantages as well.

The survey of Suddle et al. (2003) showed that safety measures against fires, release of toxic gasses and collisions with the main structure of the building above the infrastructure can easily be realised. 

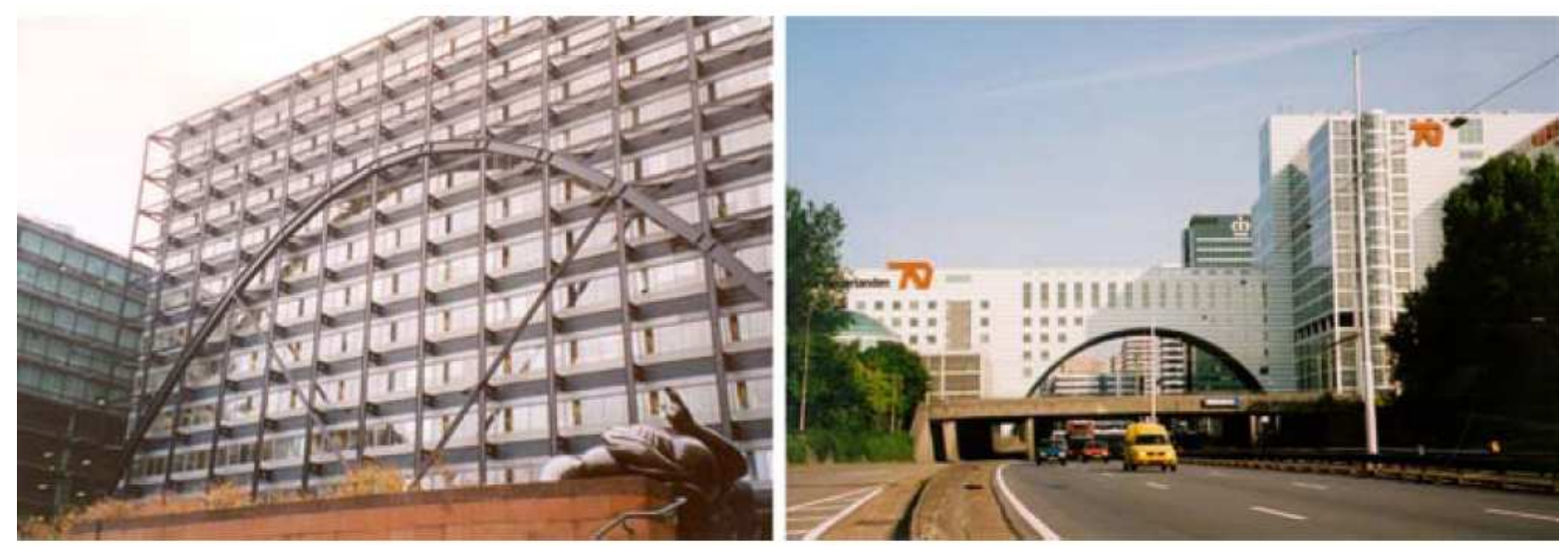

Figure 5. Examples of structural measures in buildings; Exchange House in London, UK (left) and the Haagse Poort in The Hague, The Netherlands.

In contrast, measures against explosions are both structurally and financially impossible to realise in practice. It should be seriously considered that the transport of materials that can cause an explosion, such as LPG or ammonia, does not harmonise with urban development near or above such transport routes. So, one should concentrate on pro-active and logistic measures by which explosions are prevented. In this regard, it has been persuasively proposed to separate the hazardous material causing an explosion from urban activities and vice versa, especially in the Netherlands. Furthermore, measures against toxic gasses are possible but less cost effective than measures against fire.

Therefore, separation of the transport of toxic gasses through urban development areas is optional as well. This can reduce the risk for the urban development surrounding the infrastructure.

\section{The effect on safety by spatial configuration of the covered infrastructure}

Given the fact that transport of hazardous materials is allowed in urban areas, the building and infrastructure parameters can be influenced by their spatial configuration. This will result in the variation of both the form of the (individual) risk contour and the group risk for the building above the infrastructure and for the vicinity. The main influencing (functional) building and infrastructure parameters are the width and height of the covered infrastructure, possibly combined with the length of the covered infrastructure and the height level of the infrastructure. These influencing parameters form a main part of the functional and prevention measures. By implementing functional measures, effective results can be achieved, but they have consequences for the design of the buildings and the area.
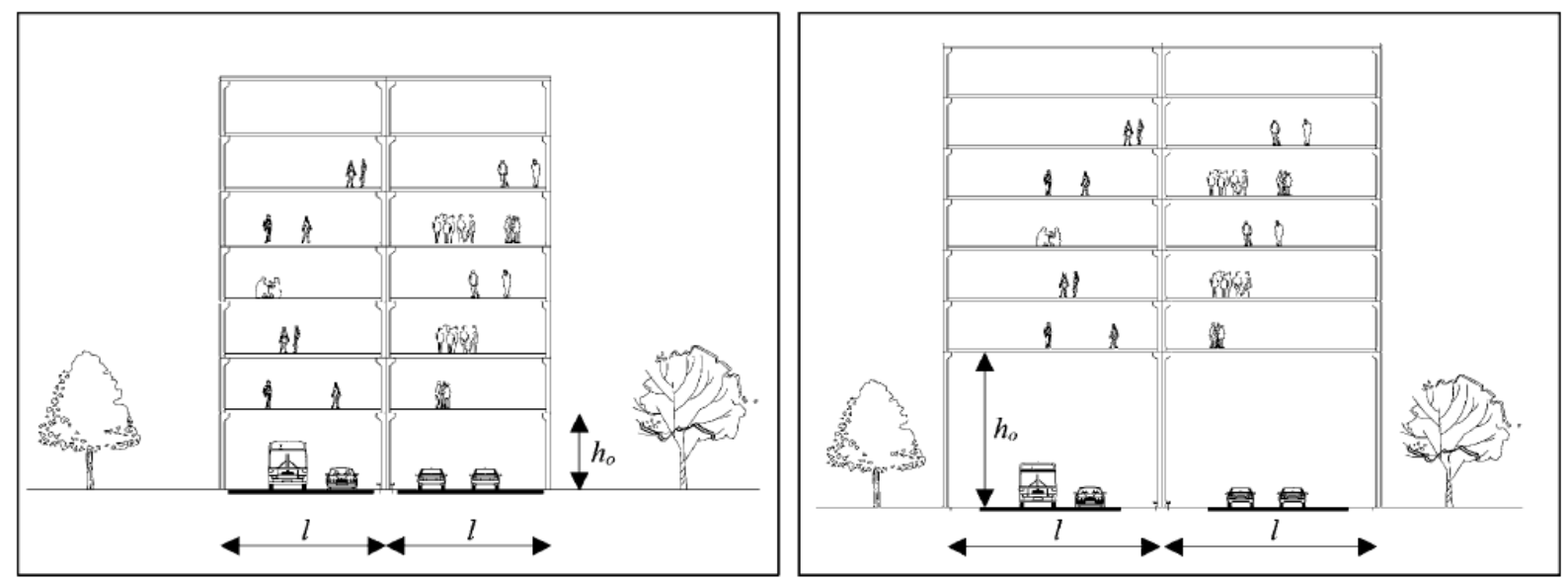

Figure 6. The height of the lowest storey of the building and the width of the building: standard variant (left) and the variant with a higher lowest storey and a bigger width (right). Source: Suddle (2004).

The height of the covered infrastructure depends on the height of the lowest storey of the building ho. The width of the covered infrastructure depends on the span I of the building. These two parameters 
form the basis for the possible scenarios at the infrastructure. Suppose ho is designed at a minimum of $4 \mathrm{~m}$. This can create problems for truckdrivers on roads, resulting in accidents (Suddle et al., 2004). Implementing a large diameter (a high level for the lowest storey ho and a bigger span I) in the design of the building means, e.g. in case of fire on the infrastructure, that the consequences are smaller (Figure 6).

Table 4. The effect of the covered length of infrastructure on the damage to the building above the infrastructure and the vicinity

\begin{tabular}{lllll}
\hline Covered Length & $\begin{array}{l}\text { Explosive } \\
\text { materials }\end{array}$ & $\begin{array}{l}\text { Release of toxic } \\
\text { gasses }\end{array}$ & $\begin{array}{l}\text { Collisions with } \\
\text { structure/buildin } \\
\text { g }\end{array}$ & Fires \\
\hline Large & -- & + & - & + \\
Small & 0 & 0 & 0 & 0 \\
\hline
\end{tabular}

Source: Adapted from Suddle (2004).

Multiple land use becomes interesting when the infrastructure is covered for long distances (Suddle et al., 2004). This is, however, not always feasible because of urban and spatial limits and safety considerations. The effect of the covered length of infrastructure on the main hazard scenarios is presented in Table 4. One can read there that a small covered length of infrastructure has a positive effect on the explosion scenario.

Any advantages regarding toxic gasses are, however, not seen when the covered length of the infrastructure is small.

If the transport of explosive materials is prohibited, one can cover infrastructure for longer distances. When the infrastructure is covered for long distances by a building, some hazards can be enclosed in the infrastructure. In this regard, both the individual and the group risk for the surroundings can decrease in comparison with the building above the infrastructure. Both the individual and group risk increase for the surrounding area at both ends of the covered infrastructure. This decrease and increase must be compared with each other in order to determine whether the risk increases when building above infrastructure. An example of the shield that is formed by covering the infrastructure as a safeguard against toxic gasses is shown in Figure 7. This is, however, not valid for small coverings.

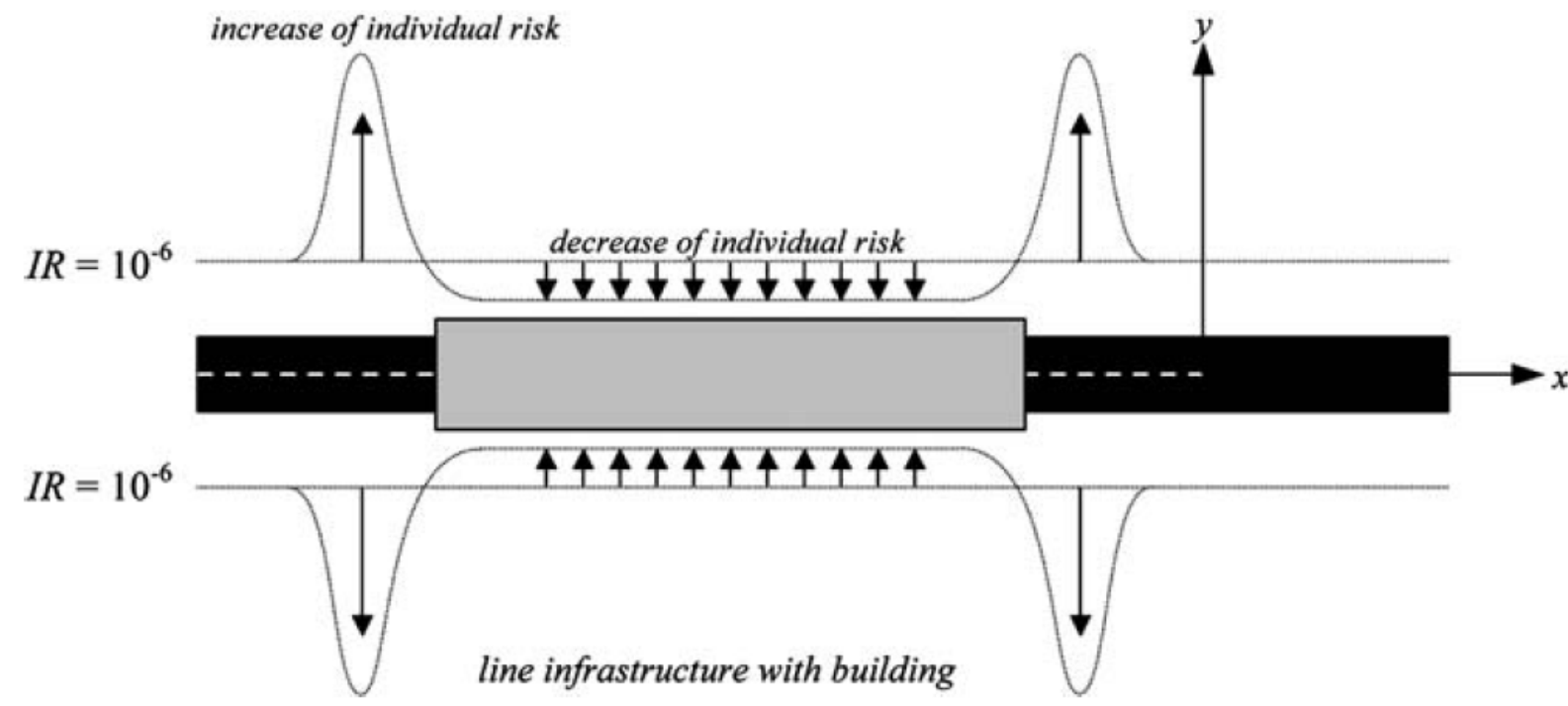

Figure 7. Local decrease and increase of individual risk contour IR by enclosing infrastructure for toxic gasses. Source: Adapted from Suddle (2004). 


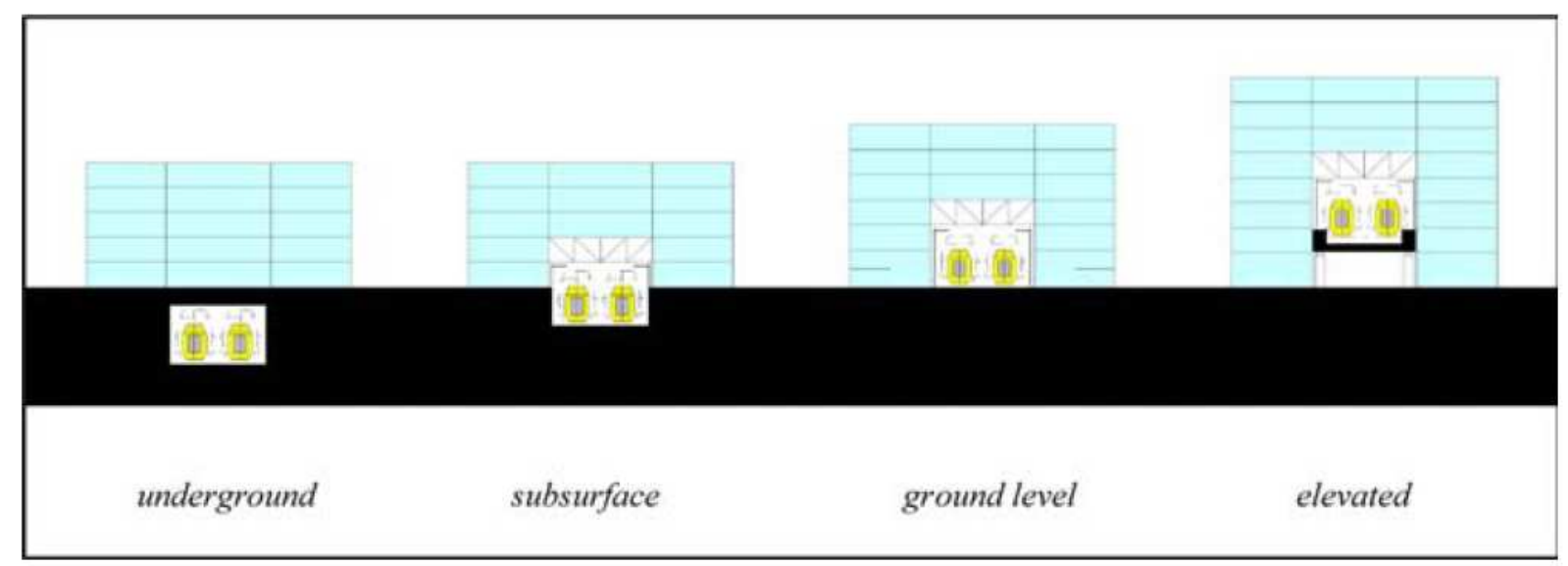

Figure 8. Different positions in height of railway infrastructure. Source: De Wilde (2002).

According to De Wilde (2002) four levels of height for infrastructure can be distinguished:

underground, subsurface, ground level and elevated. In Figure 8, these different positions are drawn for railway infrastructure. The effect of the level of infrastructure on the damage to the building above it and to the vicinity is shown in Table 5, based upon research results of Suddle (2004). The higher the level of the infrastructure, the greater the damage and thus the higher the risk for the building above. For instance, if the infrastructure is elevated, the damage to the building above it is greater (in Table5 represented as ++ ) than the situation when it is deep in the underground. The reason is that the interaction of the infrastructure and the building becomes smaller when the infrastructure is laid deep in the underground. Moreover, if the infrastructure is located deep in the underground, the damage and the effects of the hazards on the surroundings are much smaller than when the infrastructure is elevated.

Table 5. The effect of the level of infrastructure on the damage to the building above the infrastructure and the vicinity (+ means greater damage)

\begin{tabular}{lllll}
\hline $\begin{array}{l}\text { Level of } \\
\text { infrastructure }\end{array}$ & $\begin{array}{l}\text { Explosive } \\
\text { materials }\end{array}$ & $\begin{array}{l}\text { Release of toxic } \\
\text { gasses }\end{array}$ & $\begin{array}{l}\text { Collisions with } \\
\text { structure/building }\end{array}$ & Fires \\
\hline Underground & 0 & 0 & 0 & 0 \\
Subsurface & + & + & 0 & 0 \\
Ground level & + & + & + & + \\
Elevated & ++ & ++ & + & ++ \\
\hline
\end{tabular}

Source: Adapted from Suddle (2004).

\section{Conclusions}

This paper shows that accidents with transport of hazardous materials, even with a small probability of occurrence, may lead to a disaster, resulting in large consequences (fatalities) and social disruption. Therefore, safety aspects should be properly analysed and safety measures should be taken. There is a strong need for measures which could stimulate the continuity of both the transport of hazardous material and the urban development above those transport routes. In this regard, an analysis of safety measures of the safety chain combined with some spatial safety measures, which are applicable to multiple land use, are discussed in this paper.

If we focus on the exploitation stage of such projects, collisions, fires, explosions and leaks of toxic substances are the main hazards occurring on the infrastructure (consecutively decreasing in probability and increasing in consequences). Spatial measures against fires and collisions against the main structure of the building along or above the infrastructure can be developed, while measures against explosions/peak overpressure are structurally (and financially) impossible to realise in practice. Measures in buildings against the release of toxic gasses can be realised but are not expected to be cost effective. Therefore, it is sometimes better to consider pro-active and logistic safety measures concerning the regulation of the transport of hazardous materials. If it is possible to separate the 
transport of hazardous materials from the urban areas, then the logistic measures can be taken along with structural measures in buildings. Thereby, multiple land-use projects can easily be realised and the transport of hazardous materials can be increased.

The paper shows that there are numerous means to increase physical safety. Yet, implementing single measures is mostly not very effective and probably rather expensive, since individual measures might be beneficial in one hazard scenario while having no or an opposite effect on another. As a consequence, it is important to consider the implementation combinations of measures from the safety chain. In general, it can be concluded that for multiple land-use projects, small lengths of covered underground infrastructure are preferred in physical safety terms to large covered lengths or ground-level or elevated infrastructure. Covered infrastructure, though expensive, has the added advantage of increasing the building volume, making it more likely to compensate for additional costs.

\section{References}

Ale, B.J.M. (2003) Achtergrondstudie; Risico's en veiligheid, Een historische schets, Faculty of Technology, Policy and Management, Delft University of Technology, Delft (The Netherlands).

De Wilde, Th.S. (2002) Meervoudig ruimtegebruik en spoorinfrastructuur: Gebiedsontwikkeling en voorbeeldprojecten, Holland Railconsult, Utrecht, The Netherlands.

Ministerie van Binnenlandse Zaken en Koninkrijkrelaties (BZK) (2000) Leidraad maatramp, SAVE \& Van Dijke, Apeldoorn.

Meijer, F. and Visscher, H.J. (2001) Bouwveiligheid en bouwhinder bij meervoudig stedelijk ruimtegebruik, Delft University Press, Delft, The Netherlands.

OECD (2001) Safety in Tunnels, Transport of Dangerous Goods through Road Tunnels, OECD Publications, Paris.

RIVM, (1998) Yearly Environmental Report 1998, Research for Man and Environment, RIVM, Bilthoven, The Netherlands.

Suddle, S.I. (2001) Veiligheid van bouwen bij Meervoudig Ruimtegebruik, Master thesis, Civil Engineering and Geosciences. Delft University of Technology, Delft, The Netherlands.

Suddle, S.I. and Waarts, P.H. (2003) The Safety of Risk or the Risk of Safety? In: Safety and Reliability 2003, Proceedings of ESREL 2003, European Safety and Reliability Conference 2003, Vol. 2 (Eds, Bedford, T. and van Gelder, P.H.A.J.M.), Swets \& Zeitlinger, Lisse, The Netherlands, pp. 1511-1518.

Suddle, S.I., Ale, B.J.M. Waarts, P.H. and Weerheijm, J. (2003) A Quantitative Introduction of Physical Safety Measures for Realising Buildings Above Roads And Railway Tracks. In: Proceedings of Congress 25th ESReDA SEMINAR 2003 on Life Time Management of Structures, Paris, France, November 17-18.

Suddle, S.I. (2004) Physical Safety in Multiple land use. Ph.D. Dissertation, Delft University of Technology, Delft, The Netherlands. Also downloadable from URL: http://www.waterbouw.tudelft.nl/public/gelder/thesis_suddle.pdf.

Suddle, S.I., de Wilde, Th.S. and Ale, B.J.M. (2004) The 3rd dimension of risk contours in multiple land use, In: Proceedings of Congress 23rd ESReDA SEMINAR 2002 on Decision Analysis: Methodology and Applications for Safety of Transportation and Process Industries (Ed, Lannoy, A.), Delft University of Technology, The Netherlands, pp 43-54.

Raad voor Verkeer en Waterstaat \& VROM-raad (V\&W/VROM), (2003) Verantwoorde risico's, veilige ruimte, Drukzaken Rotterdam, Rotterdam.

Ministerie van VROM, (2001) Ruimte maken, ruimte delen: Vijfde Nota over de Ruimtelijke Ordening 2000/2020, Ministerie van VROM, Den Haag.

Vlek, C.A.J. (1995) Understanding, accepting and controlling risks: A multistage framework for risk communication, European Review of Applied Psychology, 1, 49-54. 